\title{
The Effect of Counterfeits on the Perceptions toward Luxury Fashion Brands
}

\author{
MiYoung Lee ${ }^{\dagger}$ \\ Dept. of Fashion Design \& Textiles, Inha University \\ Received October 26, 2011; Revised December 12, 2011; Accepted December 23, 2011
}

\begin{abstract}
This study explores if consumer perceptions about genuine luxury fashion merchandise are affected by the presence of counterfeits. A total of 504 consumers participated in an online survey. First, respondents were asked to indicate whether or not they agreed that counterfeits negatively affect genuine luxury fashion brands and to provide reasons for their responses. Approximately 57\% replied that counterfeit goods negatively affect the image of genuine luxury fashion brand goods. The main reason mentioned was that counterfeit products damage the producer/copyright holder of genuine products, as well as the national economy; they believed that it damaged the genuine luxury brands' image due to the luxury goods becoming less rare; however, $43 \%$ of respondents stated that counterfeits did not negatively affect genuine luxury fashion brands. Thus, counterfeit availability reflects that a brand is renowned and popular in a market where consumers can recognize genuine luxury fashion products from counterfeits. Second, the respondents were asked about specific luxury fashion brands and indicated that seeing counterfeits did not negatively affect genuine luxury fashion brands' value, brand reputation or satisfaction of ownership. The majority of respondents disagreed that the availability of counterfeits negatively affects the value, reputation and satisfaction of owning original luxury brands.
\end{abstract}

Key words: Counterfeits, Counterfeiting, Luxury brand, Fashion, Brand perception

\section{Introduction}

Despite the recent global recession, the domestic luxury product market is growing significantly in Korea and Korea is one of the fastest growing luxury markets in the world ("Seoul emerges", 2010). Despite the low consumption sentiment due to the recent economic recession, the sales of luxury goods have gone up rapidly. Every year since 2006, sales of luxury goods in South Korea have risen at least $12 \%$, to an estimated $\$ 4.5$ billion in 2010 ("Retail sales figure", 2011). According to McKinsey's survey, the percentage of household that luxury consumers on luxury is already higher in South Korea (5\%), than in Japan (4\%)-and

\footnotetext{
Corresponding author

E-mail: mylee@inha.ac.kr

This work was supported by INHA UNIVERSITY Research Grant.
}

the Japanese luxury market has been stagnant in recent years. As a result, department stores and shopping malls are renovating their stores by opening new luxury wings or increasing the retail of luxury brands in Korea ("Korea's luxury market", 2011).

With the growth in the luxury market, the problem of counterfeit goods has also grown. In 2008, 3,302 cases of counterfeit goods were investigated. Approximately 2,800 people were arrested for selling counterfeit goods in 2007 - 4.5 times more than in 2005 - which is indicative of how counterfeit products are becoming a serious social problem in Korea ("Catch the counterfeits!", 2007). The value of international counterfeit product deals is estimated to be valued at 700 billion dollars a year and accounts for 5-7\% of world trade, making counterfeits a significant problem on a global scale (Wotherspoon \& Cheng, 2009). According to the US Customs, the rankings of countries that are sources of 
products which are counterfeit or have fake labels are China, Hong Kong, and Korea; the emerging nations in Asia consist of the bulk of counterfeit goods production, distribution and selling, and the EU pegs Korea to be the greatest exporter of counterfeit goods among OECD nations. Thus, it is known to be a major exporter of counterfeit products ("Catch the counterfeits!", 2007).

Counterfeit goods are defined as cloned products that are identically packaged with the label or trademark of genuine ones. They are duplicates of legal products that include appearance, packaging, trademark, and label (Ang et al., 2001; Kay, 1990). These kinds of fake goods are not limited to fashion products, but can also be found in pharmaceuticals, machine parts, films, music albums, computer software, and a variety of other products. The term counterfeit is used alongside various words such as imitation, fake, copy, and knockoff, with legitimate goods used as the opposite concept; however, they are categorized according to the state or degree of the duplicate. Imitation goods are very similar to original goods; however, they have house labels rather than the labels of the original goods. Thus, imitation goods copy the function and design of popular products, but they improve the existing product, and thus include creative adaptation, which adds a new economic factor. Knock-offs are produced using the same characteristics as the genuine good, but are different from the genuine good in that they are distributed at far lower prices, and are mostly defined as low-quality products (Nill \& Shultz, 1996).

Although the production and distribution of such counterfeit goods are considered punishable for the violation of intellectual property under the trademark laws in Korea (Kim, 2009), counterfeiting highly visible and well-known luxury fashion brand goods can easily be seen on the streets of major cities. There are consumers who buy counterfeits, thinking that they are genuine. However, in many cases of the luxury fashion brand market, they are fully aware that the goods bought are counterfeit. One of the main factors as to why these consumers purchase counterfeit goods is the financial factor. Counterfeit goods are notably cheaper compared to genuine ones, so consumers evaluate the value of counterfeits to be high compared to their prices, thus allowing consumers who cannot own genuine goods due to their financial limitations to satisfy their material desires for low prices.

The common opinion is that the production, distribution, and selling of counterfeit goods has negative effects, such as damaging the image of genuine goods, worsening their reputation, decreasing their sales, and lessening their chances of opportunities to make a profit (Bloch, et al., 1993; Hong \& Suk, 2009; "The economic impact", 2007). However, there is also the opposite opinion claiming that counterfeit goods are a condition to climbing the luxury rank, and since counterfeits appear because the product is the envy of the public, original manufacturers could financially benefit from the advertising effect of counterfeiting, which may increase brand awareness (Hustak, 1990; Nia \& Zaikowsky, 2000; Yao, 2005). Some say that counterfeiters are not taking away customers of luxury brands, because conumers who buy counterfeits cannot afford the legitimate ones in the first place (Hustak, 1990). Despite the fact that the most common form of counterfeit good is fashion goods, there have not been any actual research studies on how counterfeit goods' impact luxury fashion brands in Korea. Thus, the purpose of this research is to explore how counterfeiting of luxury brands affects the consumers' perceptions of luxury brands in Korea.

\section{Literature Review}

\section{Counterfeit Products}

Despite efforts of the government and companies to clear the market of counterfeit goods, the size of the counterfeit goods market is growing. Korea has a long history in the production of counterfeits, and as a result, it is likely that Korean participants would have some experience with purchasing counterfeits. According to previous research about consumers' buying habits of counterfeit goods, most Korean consumers have shown to have experience in this area (Lee \& Johnson, 2007; Yu \& Lee, 2002), and it is significantly higher compared to the proportion of foreign consumers who have purchased counterfeit goods. Due to the pervasiveness of counterfeit goods in the Korean market, consumers may have more experience in purchasing and owning counterfeit merchandise. 
These consumers visit markets where counterfeits are offered for sale. Thus, the main purpose of counterfeiting could be to satisfy those consumers'needs and wants rather than to deceive consumers into thinking that they are buying genuine goods (Arellano, 1994). There are also studies showing that people buy counterfeit goods not because of financial factors, but because they share the image, design, or fashion sense of the luxury fashion good (Alber-Miller, 1999; Wee et al., 1995; Yu \& Lee, 2002).

According to a previous study, attitudes toward counterfeit goods depend on consumers'characteristics. If the buyers of counterfeit goods feel that the purchase of a counterfeit is not dangerous and has enough value, they will be more willing to buy counterfeits again, and they tend to: have high hedonic shopping values; be male; be younger in age; have less education; and earn lower incomes than consumers who do not buy counterfeits (Ang et al., 2001; Bloch et al., 1993; Kwong et al., 2003; Tom et al., 1998). Tom et al. (1998) also found that consumers who had purchased counterfeits held positive perceptions toward counterfeiting and intended to purchase counterfeits in the future. S. H. Lee (2004) also found that counterfeit purchasers tended to purchase counterfeit goods as an alternative to genuine items and did not feel guilty about their purchases. Compared to nonpurchasers, counterfeit purchasers held more positive attitudes toward the illegality of manufacturing, selling, and buying counterfeits.

Considering the effects of one's personal moral consciousness, consumers with a strong sense of morals decidedly try to avoid buying counterfeit goods, while consumer with a low sense of morals do not think of themselves as responsible when buying counterfeits, but hold sellers of counterfeit goods responsible (Cordell et al., 1996; Kwong et al., 2003). Chan et al. (1998) investigated the ethical beliefs of Chinese consumers in Hong Kong. They found that these participants tended to view buying counterfeits as "not wrong," even though selling counterfeits is illegal in Hong Kong. Lu and Lu's study (2010) of 230 Indonesians found that consumers' ethical orientation affected their questionable actions: analytical results indicated that Indonesians with high materialism and relativism were more likely to engage in actions that were questionable, but legal.

\section{How Counterfeit Goods Affect Legitimate Goods}

In general, it is known that counterfeit goods damage the reputation of legitimate goods through low-quality production or distribution. They also decrease the sales of legitimate goods, thereby negatively affecting the manufacturers of legitimate goods and harming proper businesses in society overall-in general, they negatively affect the nation, economy, and society (Bloch et al., 1993; "The economic impact", 2007).

Governmental concerns regarding counterfeits center on the following reasons: 1) counterfeiting negatively impacts innovation; 2) it threatens the welfare of consumers; and 3) it is used as a resource for criminal networks, organized crime and terrorist groups. In terms of business, those consumers who believe they are buying genuine articles when in, in fact, they are counterfeits, will likely blame the manufacturer of the genuine brand goods if the counterfeit items do not meet their expectations. In addition, the proliferation of counterfeit versions of luxury goods can make the genuine articles less desirable to their traditional consumers. Thus, counterfeiting has a negative impact on sales and licensing; brand value and reputation; and customer loyalty. It also increases costs due to spending efforts to combat counterfeiting; and produces less incentive to invest in new products and processes. From the consumer side, the significant health and safety risks that substandard counterfeit and pirated products could pose to those who consume the items; and the lower consumer utility due to a generally lower quality of the infringing products are major concerns ("The economic impact", 2007). In prior research, genuine brand manufacturers and researchers (Bloch et al., 1993; Chakraborty et al., 1997) claimed that counterfeits devalue the genuine brand image and provide a negative impact on brand equity, reputations, and increase the cost of genuine product marketing. Through indepth interviews with 40 luxury brand consumers in Thailand and India, Commuri (2009) revealed that genuine luxury consumers are not indifferent to the proliferation of counterfeits. When luxury consumers are faced with counterfeit proliferation, they adopt one of three strategies: "flight" (abandoning a brand in favor of new ones), "reclamation" (elaborating descriptions of pioneering 
brand patronage), or "abranding" (disguising all brand cues). Counterfeit proliferation causes the potential loss of exclusivity and prestige of luxury brand images, and it drives away the consumption of genuine luxury brands from the actual brand.

Some researchers have found that the impact of counterfeits depends on the counterfeit characteristics (e.g., quality) or consumer type. D. D. Lee (2004) examined the effects of quality and price of counterfeits on consumer evaluations of counterfeit and genuine luxury brands by four consumer groups-a substitute group, an economy group, an ethical group, and an aristocratic group. For ethical and economy group consumers, the quality of counterfeits have a significant effect on the evaluation of genuine luxury brands. In the study examining the effect of attitudes toward fashion counterfeits on brand attachment and equity, Lee and Kim (2007) found that attitudes toward fashion counterfeits had a negative effect on brand attachment and equity. Yoo (2011) investigated the impact of counterfeiting on consumers' attitudes toward luxury brands. One-hundred female consumers (50 counterfeit-item consumers, 50 genuine-item consumers) were asked to evaluate a luxury brand repeatedly before and after exposure to counterfeiting stimuli-a newspaper article of the counterfeiting proliferation of the luxury brand. The study found that the impact of counterfeiting toward luxury brands depends on the types of consumers: counterfeiting has a negative impact on the attitudes of genuine-item consumers, while it has an insignificant impact on that of counterfeit-item consumers. However, since the stimuli used were newspaper articles containing news on counterfeiting proliferation and prosecuting counterfeit offenders, there is the possibility that the responses could have been affected not only by the counterfeiting proliferation, but also by the news of counterfeiting illegality.

On the other hand, Barnett (2005) and Yao (2005) highlighted that companies may experience increased brand awareness, as well as additional demand due to bandwagon and network effects. Since the luxury fashion good is a source of envy to the public, there are counterfeit goods that can benefit from advertising or bandwagon effects. Ultimately most buyers of counterfeit goods cannot afford to purchase legitimate luxury goods, so there are claims that counterfeit goods do not actually reduce the sales of luxury items. Conner and Rumelt (1991) support the notion that illegally counterfeited software will promote a positive effect to expand the products' market share. According to a study by Nia and Zaikowsky (2000), authentic luxury fashion good consumers who were surveyed are well aware of the quality and characteristics of luxury goods; therefore, the value, status, and satisfaction of legitimate luxury fashion goods do not decrease by the wide availability of counterfeits. Further-more, the majority of respondents disagreed that the availability of counterfeits negatively affects their purchase intentions for original luxury brands. Recently, Yoo and Lee (2011) examined the effect of past experiences involving counterfeit or genuine luxury brands on the purchase intentions of counterfeit or genuine luxury brand items through a survey of 400 female university students. They found an asymmetrical effect that past experiences with genuine luxury brands are negatively related to the purchase intentions of counterfeit luxury brands, while past experiences with counterfeit luxury brands do not relate to the purchase intentions of genuine luxury brands.

Although, there is some previous research concerning the effect of counterfeits on genuine luxury brands in Korea, the research findings on the effects of counterfeits regarding genuine brand images are inconsistent, and more research is needed. While women remain the primary luxury market, a new luxury market for men is emerging in Korea, and department stores have designated a special section to cater to their growing needs (“Korea's luxury market”, 2011). Recent research investigating the effect of counterfeits on luxury brands examined consumers' purchasing intentions toward counterfeit or genuine luxury brands (Yoo \& Lee, 2011), and most previous research in Korea has investigated female samples only. As a result, more research with both male and female samples examining the how counterfeiting may affect consumers' perceptions of luxury brands is needed.

\section{Methods}

\section{Research Questions}

Based on the literature review, the research frame- 
work for this research was developed $<$ Fig. $1>$, and the research questions include the following:

1) What are the general perceptions of the effects of counterfeits regarding luxury fashion brands? and

2) For people who have come in contact with counterfeits of fashion luxury brands, how does the counterfeiting of luxury brands affect consumers' perceptions toward luxury fashion brands-the brands' value, reputation, and satisfaction of owning the products?

\section{Measurements}

The questionnaire was developed based on the work of previous researchers (Ang et al., 2001; Ha \& Lennon, 2004; Nia \& Zaikowsky, 2000). The questions included: 1) participants' purchasing experiences of counterfeit or genuine goods (i.e., whether or not one purchased them, name of the brands, number of purchases, location of purchases, and types of products 2 ) general perceptions of the effects of counterfeits regarding luxury fashion brands; and 3) how exposure to actual luxury fashion brand counterfeit goods affected their evaluations of legitimate brands' value, reputation and satisfaction of owning them.

In order to find the luxury fashion brands that were familiar to consumers and to find the luxury fashion brands whose genuine products and counterfeits were both available in the Korean marketplace, preliminary 5 focus group interviews with 35 consumers were conducted. From the preliminary study, the "Chanel" brand was selected for the survey. For questions concerning the impact of counterfeits toward legitimate goods, how exposure to counterfeit goods affected evaluations of legitimate goods was measured by "value of the

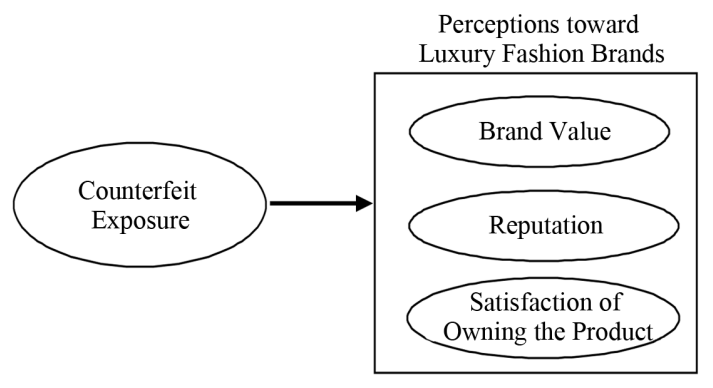

Fig. 1. Research framework. luxury good," "reputation of the luxury good," and "satisfaction of owning the luxury good," using a 7-point scale $(1=$ much worse than before, $7=$ much better than before). The satisfaction of owning a luxury good was asked only to those who owned luxury brand goods.

\section{Sampling and Data Analysis}

The data were collected via an online survey by a research firm. A total of 504 consumers participated in this survey. Previous research (Chang \& Lee, 2007) suggested that females tend to have more experience than males, and approximately $40 \%$ of general consumers (including both males and females) were counterfeit consumers. Thus, in order to have a wide age range for the sample, quota sampling for gender (male: female $=2: 3$ ), age (20s:30s:40s=1:1:1), and counterfeit purchase experience (with experience:without experience $=3: 2$ ) factoring was used. For the data analysis, descriptive statistics, cross-tab, and Logit analyses were used.

\section{Sample Characteristics}

A total of 504 consumers ( 300 female, 204 male) completed the questionnaire. Detailed information about the samples' demographic characteristics is presented in $<$ Table $1>$. Close to $56.5 \%$ indicated that they had experience in purchasing luxury brand items. Approximately $60 \%$ of the participants indicated that they had purchased counterfeit products. Interestingly, more male participants had counterfeit purchasing experience (Male: $75 \%$, Female: $49 \%$ ).

Handbags (29.8\%), clothing (28.8\%), wallets (27.2\%), and shoes/sneakers $(18.7 \%)$ were the most frequently purchased fashion counterfeits. A majority of the respondents indicated that they had two $(20.8 \%)$ or three (11.1\%) counterfeit goods. The primary reason offered for purchasing counterfeit goods was their low cost and the desire to have luxury products.

Respondents' experiences in purchasing luxury fashion brand goods (counterfeit or genuine goods) are presented in $<$ Table $2>$. Nearly $24 \%$ of the respondents indicated that they had purchased both genuine, as well as counterfeit luxury brand products, while $40 \%$ of 
Table 1. Sample characteristics $\quad(N=504)$

\begin{tabular}{|c|c|c|c|}
\hline \multicolumn{2}{|r|}{ Characteristics } & Frequency & $\%$ \\
\hline \multirow{2}{*}{ Gender } & Male & 204 & 40.5 \\
\hline & Female & 300 & 59.5 \\
\hline \multirow{3}{*}{ Age } & 20 's & 168 & 33.3 \\
\hline & 30 's & 168 & 33.3 \\
\hline & More than 40 & 168 & 33.3 \\
\hline \multirow{6}{*}{$\begin{array}{l}\text { Occupa- } \\
\text { tion }\end{array}$} & Students & 66 & 13.1 \\
\hline & Office workers & 176 & 34.9 \\
\hline & Professionals & 19 & 3.8 \\
\hline & Housewives & 88 & 17.5 \\
\hline & Own business & 40 & 7.9 \\
\hline & Service/Production & 46 & 9.1 \\
\hline \multirow{6}{*}{$\begin{array}{l}\text { House- } \\
\text { hold } \\
\text { Income } \\
(1,000 \\
\text { Won) }\end{array}$} & Less than 1,000 & 27 & 5.4 \\
\hline & 1,000 -less than 2,000 & 101 & 20.2 \\
\hline & 2,000 -Less than 3,000 & 113 & 22.2 \\
\hline & 3,000 -Less than 4,000 & 134 & 26.6 \\
\hline & 4,000 -Less than 5,000 & 67 & 13.3 \\
\hline & Less than 5,000 & 62 & 12.3 \\
\hline & Total & 504 & 100.0 \\
\hline
\end{tabular}

respondents indicated that they had neither purchased genuine luxury fashion goods, nor counterfeit goods.

\section{Results}

\section{The Effects of Counterfeit Goods on the Per- ceptions of Luxury Fashion Goods: Con- sumers' General Opinions}

To discover whether counterfeits affect consumers' perceptions of legitimate goods, we first determined if the purchase of counterfeits negatively affected the image of legitimate luxury goods, and if so, why the participants thought so. The respondents were asked whether they thought counterfeits negatively affected legitimate luxury fashion brands, and 57\% $(n=288)$ agreed that counterfeits created a negative effect to consumers' perceptions toward genuine luxury fashion brands.

Among those who agreed that counterfeits created a negative affect, 216 respondents provided reasons for their responses, and these were categorized into three groups: they thought that counterfeits created a negative impact to genuine fashion goods because counterfeit products damage the producer/copyright holders for the genuine products, as well as the country's economy; they also damage the genuine luxury brands' image, and counterfeits are a crime due to trademark violation. On the other hand, $43 \%$ agreed that counter feits do not negatively affect genuine luxury fashion brands because counterfeit availability is an indicator of "renown and popularity" among consumers. These respondents reasoned that consumers can recognize the difference between counterfeits and genuine products, and that the counterfeit and genuine luxury fashion brand markets are completely different, in that counterfeit consumers cannot afford to purchase genuine luxury fashion goods (Table 3 ).

Logistic regression analysis was used to model dichotomous responses: counterfeiting goods do (or do not) create a negative impact on genuine fashion brands. The results indicate that age (wald $=12.353, p=.00$ ), experience of purchasing luxury fashion counterfeits (wald= 15.393, $p=.00$ ), and experience of purchasing genuine luxury fashion goods ( wald $=6.644, p=.01$ ) were significant factors (Table 4). Respondents' income level or sex was not a significant factor. Consumers who were older, with previous experience in purchasing genuine goods, and with no prior experience in purchasing counterfeit luxury brand goods tend to believe that counterfeit goods negatively affect the image of legitimate luxury goods. These results support Yoo's (2011) finding that counter-

Table 2. Consumers experience of purchasing luxury fashion brand goods

\begin{tabular}{c|c|c|c|c}
\hline \hline \multicolumn{2}{c|}{ Consumer characteristics } & \multicolumn{2}{|c}{$\begin{array}{c}\text { Experience of purchasing genuine } \\
\text { luxury fashion brand products }\end{array}$} & \multirow{2}{*}{ Total } \\
\cline { 3 - 5 } \multicolumn{2}{c|}{} & Yes & $84(16.7 \%)$ & 204 \\
\hline $\begin{array}{c}\text { Experience of purchasing counterfeit } \\
\text { luxury fashion brand products }\end{array}$ & Yes & $120(23.8 \%)$ & $201(39.9 \%)$ & 300 \\
\cline { 3 - 5 } & No & $99(19.6 \%)$ & 285 & 504 \\
\hline
\end{tabular}


Table 3. Impact of counterfeits on genuine luxury fashion brands

\begin{tabular}{|c|c|c|}
\hline Opinion & Impact & Frequency (\%) \\
\hline \multirow{3}{*}{$\begin{array}{l}\text { Negative impact } \\
\quad(n=216)\end{array}$} & $\begin{array}{l}\text { Damage to the producer/copyright holder and economy } \\
\text { - Decrease the company's will to develop new products } \\
\text { - Decrease sales volume } \\
\text { - Damage to the country's economy }\end{array}$ & $\begin{aligned} 10 & (4.6) \\
8 & (3.7) \\
7 & (3.2)\end{aligned}$ \\
\hline & $\begin{array}{l}\text { Damage to genuine luxury brands' image } \\
\text { - Cannot recognize genuine from counterfeit products } \\
\text { - Look like low-quality goods } \\
\text { - Damage the brand value } \\
\text { - Damage the brand image } \\
\text { - Decrease the reliability of genuine luxury goods } \\
\text { - Decrease the rarity of the luxury brands in the market }\end{array}$ & $\begin{array}{l}23(10.6) \\
40(18.5) \\
48(22.2) \\
32(14.8) \\
20(9.3) \\
20(9.3)\end{array}$ \\
\hline & $\begin{array}{l}\text { Counterfeiting is a crime } \\
\text { - Unethical behavior } \\
\text { - Crime }\end{array}$ & $\begin{array}{l}2(0.9) \\
6(2.8)\end{array}$ \\
\hline \multirow[b]{2}{*}{$\begin{array}{l}\text { No-ne gative impact } \\
\qquad(n=152)\end{array}$} & $\begin{array}{l}\text { Counterfeits reflect that the brand is renowned. } \\
\text { - Counterfeits reflect that the brand is famous. } \\
\text { - Counterfeits expand the luxury brand market. }\end{array}$ & $\begin{array}{r}52(34.2) \\
5(3.3)\end{array}$ \\
\hline & $\begin{array}{l}\text { Counterfeits are counterfeits. } \\
\text { - Counterfeits are counterfeits: Genuine products have a higher value. } \\
\text { - The counterfeit and genuine luxury fashion brand markets are different. } \\
\text { - Consumers can recognize genuine luxury fashion products from counterfeits. } \\
\text { - Counterfeits have no relationship with a genuine luxury brand image. }\end{array}$ & $\begin{array}{l}51(33.6) \\
11(7.2) \\
27(17.8) \\
6(3.9)\end{array}$ \\
\hline
\end{tabular}

Table 4. The result of logistics regression analysis: whether or not counterfeits negatively influence the perception of the luxury fashion brands

\begin{tabular}{l|r|r|r|r|c}
\hline \multicolumn{1}{c|}{ Variables } & B & \multicolumn{1}{c|}{$S E$} & Wald & Sig. & Exp (B) \\
\hline Experience of purchasing counterfeit luxury fashion goods & -0.818 & .209 & 15.393 & 0.000 & 0.441 \\
\hline Experience of purchasing genuine luxury fashion goods & 0.512 & .199 & 6.644 & 0.010 & 1.669 \\
\hline Age & -0.405 & .115 & 12.353 & 0.000 & 0.667 \\
\hline Gender & 0.255 & .197 & 1.685 & 0.194 & 1.291 \\
\hline Income & 0.000 & .000 & .774 & 0.379 & 1.000 \\
\hline Constant & 1.005 & .564 & 3.171 & 0.075 & 2.732 \\
\hline
\end{tabular}

feiting has a negative impact on the attitude of genuineitem consumers, while it has an insignificant impact on that of counterfeit-item consumers.

In the next section, by posing the questions to owners of luxury fashion goods and to consumers who had seen fashion counterfeit goods, genuine luxury fashion brand manufacturers and retailers will be able to have a better understanding of the effects of counterfeiting on the demand for genuine luxury fashion brands.

\section{The Effects of Counterfeit Goods on Percep- tions of Luxury Fashion Goods: Consumers' Responses with Specific Luxury Fashion Brands}

In order to determine what kind of effects exposure to counterfeit goods has on perceptions of legitimate goods, weasked respondents who had seen counterfeit items of luxury fashion brands whether their brand perceptions changed after they were exposed to these fashion counterfeit goods. From a prestudy with 35 fashion consumers, "Chanel" fashion brands were selected as a luxury fashion brand. The respondents' brand perceptions being exposed to fashion counterfeit goods were measured with the luxury fashion brand goods' value, the brands' reputation, and satisfaction of ownership, using a 7-point scale.

Ninety-five percent of the respondents were familiar with the luxury brand "Chanel." Among them 17.4\% $(n=88)$ indicated that they had purchased genuine "Chanel" brand goods. About 51\% $(n=257)$ of respon- 
Table 5. The results of cross-tab: respondents perception of counterfeits' effect on luxury fashion brands by their experience of seeing counterfeit luxury fashion goods

\begin{tabular}{c|c|c|r|c}
\hline \hline \multirow{2}{*}{} & \multicolumn{2}{|c|}{ Experience of seeing "Chanel” counterfeits } & \multirow{2}{*}{ Total } \\
\cline { 3 - 5 } & & Yes & No & \\
\hline \multirow{2}{*}{$\begin{array}{c}\text { Counterfeits negatively affect } \\
\text { luxury fashion brand }\end{array}$} & Yes & $138(52.9 \%)$ & $152(61.5 \%)$ & $288(57.1 \%)$ \\
\cline { 2 - 5 } & No & $121(47.1 \%)$ & $95(38.5 \%)$ & $216(42.9 \%)$ \\
\hline \multicolumn{2}{c|}{ Total } & $257(100 \%)$ & $247(100 \%)$ & $504(100 \%)$ \\
\hline
\end{tabular}

Pearson $\operatorname{chi}^{2}(1)=3.822 ; p=.051$

dents indicated that they had seen "Chanel" counterfeit goods. $52.9 \%$ of respondents who actually experience of seeing "Chanel" counterfeits agreed that counterfeits negatively affected the perception of genuine "Chanel" luxury goods, while $61.5 \%$ of respondents who did not have no prior experience of seeing "Chanel" counterfeit indicated that counterfeit negatively affected the perception of genuine luxury fashion brand (Table 5). This result indicates that respondents exposed to counterfeits did not negatively affect their perceptions of luxury fashion brands.

Respondents who indicated that they had seen "Chanel" counterfeit goods $(n=257)$ were asked to indicated how exposure to counterfeit goods affected evaluations of legitimate goods was measured by "value of the luxury good," "reputation of the luxury good," and "satisfaction of owning the luxury good." The results indicated that their perceptions of the genuine luxury fashion brand were not negatively affected, and were even somewhat positively affected by the brand's value $(M=4.82)$, brand reputation $(M=4.96)$ or satisfaction of ownership $(M=4.93)$ by the availability of counterfeits of that luxury fashion brand ( $1=$ very negatively affected, $4=$ no affect, $7=$ very positively affected).
Then, responses were grouped based on the distribution of the replies involving participants' brand perceptions after seeing the brands'counterfeit goods: responses from 1-3 on the 7-point scale were regarded as a negative effect; responses of 4 were regarded as no-affect; and responses from 5-7 were treated as a positive effect. This categorization will provide more detailed information as to what percentage of respondents indicated that counterfeit goods negatively or positively affected genuine fashion brands. As can be seen in $\langle$ Table 6$\rangle$, responses in the positive effect category were almost $60 \%$, indicating that the majority of the respondents believed that seeing a fashion brand's counterfeit goods positively affected their perceptions of the brand's value, reputation and satisfaction of ownership.

Regression analyses with respondents' demographic characteristics (e.g., age, income, sex) and experience of purchasing counterfeit luxury fashion goods were performed to determine the factors affecting consumers' perceptions of luxury fashion brands after they saw that brand's counterfeit goods. Only respondents' counterfeit purchasing experience was a significant factor affecting respondents' evaluation of a luxury brand's reputation

Table 6. The effect of counterfeit goods on perceptions of genuine luxury fashion brand after being exposed to counterfeit goods

\begin{tabular}{l|l|c|c|c}
\hline \hline \multicolumn{2}{c|}{$\begin{array}{c}\text { The effect of counterfeit goods on perceptions } \\
\text { of genuine luxury fashion brand }\end{array}$} & $\begin{array}{c}\text { Product value } \\
(n=257)\end{array}$ & $\begin{array}{c}\text { Brand reputation } \\
(n=257)\end{array}$ & $\begin{array}{c}\text { Brand satisfaction } \\
(n=88)^{\mathrm{a}}\end{array}$ \\
\hline \multirow{3}{*}{$\begin{array}{l}\text { Changes of perceptions: } \\
\text { Frequency (\%) }\end{array}$} & Negative effect & $20(7.8 \%)$ & $25(9.7 \%)$ & $9(10.2 \%)$ \\
\cline { 2 - 5 } & No effect & $85(33.1 \%)$ & $69(26.8 \%)$ & $24(27.3 \%)$ \\
\cline { 2 - 5 } & Positive effect & $152(59.1 \%)$ & $163(63.4 \%)$ & $55(62.5 \%)$ \\
\hline \multicolumn{2}{c|}{$M(S D)$} & $4.82(1.168)$ & $4.96(1.291)$ & $4.93(1.371)$ \\
\hline
\end{tabular}

${ }^{a}$ Respondents who had seen "Chanel" counterfeit goods and who had purchased genuine brand goods were included for the analysis of brand satisfaction $(n=266)$. ( $1=$ very negatively affected, $4=$ no affect, $7=$ very positively affected).

${ }^{b}$ Responses from 1-3 on the 7-point scale were regarded as a negative effect; responses of 4 were regarded as no-affect; and responses from 5-7 were treated as a positive effect. 
$(\mathrm{t}=-2.224, p=.027)$, and satisfaction of ownership ( $\mathrm{t}=$ $-2.069 p=.042)$ after they were exposed to "Chanel" counterfeit. Anyone who has ever purchased a counterfeits, compared to others who do not have the experience, tends to have a positive evaluation regarding the reputation of the "Chanel" brand. In addition, respondents who own "Chanel" brand items and also has ever purchased a counterfeits tends to have a positive evaluation on the satisfaction of ownership.

\section{Discussion}

This research was intended to determine whether counterfeit goods affected consumers' perceptions' of luxury fashion brands through an online survey. First, respondents were asked to indicate whether they agreed that counterfeits negatively affected genuine luxury fashion brands or not, and to provide reasons for their responses. Approximately 57\% replied that counterfeit goods negatively affected their image of genuine luxury fashion brand goods. The main reasons mentioned were that counterfeit products damage the producer/ copyright holders for the genuine products, as well as the country's economy also, counterfeiting damages genuine luxury brands' image due to luxury goods becoming less rare. On the other hand, many respondents also replied that counterfeits do not negatively affect genuine luxury fashion brands because counterfeit availability reflects that the brand is renowned and popular on the market. They also believed that consumers can recognize genuine luxury fashion products from counterfeits, and that genuine luxury fashion brand consumers always buy genuine ones, and not counterfeits. Logistic regression analysis revealed that consumers who were older, with previous experience in purchasing counterfeit goods, and with no prior experience in purchasing genuine luxury brand goods tend to believe that counterfeit goods negatively affect the image of legitimate luxury goods.

However, when the respondents were asked about specific luxury fashion brands, they indicated that seeing counterfeits does not negatively affect genuine luxury fashion brands' value, status symbol or satisfaction of ownership. Approximately 60 percent of respondents indicated that the genuine fashion brands' value, repu- tation, and satisfaction of ownership are not negatively, and are even positively affected by the availability of counterfeits. Unlike the argument suggested by fashion brand companies or researchers (Bloch et at., 1993; Chakraborty, et al., 1997) that counterfeits negatively influence the images and properties of genuine brand items in the fashion brand market and cause the marketing cost related to genuine products to rise, consumers do not evaluate genuine products with counterfeits, since they evaluate genuine items and counterfeits differently. Even though many original brand name manufacturers believe that counterfeits harm their brand names and images, since many consumers are already aware of the value, qualities and characteristics of the genuine luxury fashion brands, the availability of counterfeits does not negatively affect consumers' perceptions toward genuine fashion brands. The findings of this study support Nia and Zaikowsky's results (2000), which stated that the value or satisfaction of legitimate luxury goods does not suffer negative effects due to counterfeits. Thus, the results indicate that counterfeits may not devalue genuine luxury fashion brands' value, reputation or sense of ownership in general.

When provided with a general type of question, more than $57 \%$ of respondents indicated that the fashion counterfeits negatively influence the genuine products by reflecting their own opinions. Meanwhile, when provided with a question which focused on the influence of a counterfeit on the specific luxury fashion brand they have seen or purchased - "Chanel" in this case - and its related counterfeits, only less than $10 \%$ of respondents who actually way than brand's counterfeit goods indicated counterfeit have negative effect on the image of genuine fashion brand. Even if consumers believe that counterfeits do have a negative influence on genuine items, such a negative influence does not seem to exist in terms of the brand value of a genuine product or the level of satisfaction for the possession of such a product in the specific state related to the counterfeits of any specific brand when a survey targeting consumers who have been exposed to the counterfeits of actual fashion brands. Previous research investigated the effect of counterfeit by questions with specific brand respondents experienced (Nia \& Zaikowsky, 2000) reported similar result. This indicated that in 
order to investigate the effects of counterfeits on luxury brands, it would be more appropriate to do research by asking questions with specific luxury brands consumers have experienced.

According to such a result, it can be said that there is not sufficient connection between consumers' belief regarding the availability of counterfeits in the market and the brand value or reputation of a genuine product, since consumers tend to recognize the design characteristics related to the luxury fashion brands, while differentiating the excellence shown by the design and quality of such brands with the one related to the design and quality of counterfeits. Thus, despite the expansion of the counterfeit business of luxury fashion brands, manufacturers and marketers of genuine luxury fashion brands should concentrate on marketing the physical and psychological advantages of their luxury products to their consumers. Luxury brand manufacturers and marketers should make efforts to create and build strong brand images and communicate those brand images of prestige and exclusivity of fashion luxury brands.

Since most fashion brand items are expensive, not targeting the general public, such items tend to show excellent designs and quality, which can be differentiated from ordinary counterfeits. Therefore, it would be necessary to carry out follow-up studies in regard to the influence of counterfeits on genuine items in case of the non-luxury fashion brands (i.e., the sportswear of famous brands) which could be purchased more easily by the general public because of their low prices. Also, it would be important to carry out a cross-national (or cross-cultural) study regarding the connection between an Asian country where counterfeits could be observed easily and the country whereit is not easy to find such items, or between a country with a high level of recognition towards intellectual properties or a high ethical standard and the country which does not show such a standard, in order to find out any difference among between those countries.

There are several limitations in the generalization of this study. Convenient quota sampling and an online survey were used in this study. Since only those with access to the Internet participated in this study, the responses may not be typical luxury fashion brand consumers. In future research various luxury brands should be included in the study in order to observe the effects that counterfeit goods have on the image of luxury brands.

\section{References}

Alber-Miller, N. D. (1999). Consumer misbehavior: why people buy illicit goods. Journal of Consumer Marketing, 16(3), 273-287.

Ang, S. H., Cheng, P. S., Lim, E. A. C., \& Tambyah, S. K. (2001). Spot the difference: Consumer responses towards counterfeits. Journal of Consumer Marketing, 18(3), 219235.

Arellano, R. (1994). Informal-underground retailers in lessdeveloped countries: An exploratory research from a marketing point of view. Journal of Macromarketing, 14(2), 21-35.

Barnett, J. (2005). Shopping for Gucci on Canal Street: Reflections on status consumption, intellectual property, and the incentive thesis. Virginia Law Review, 91(6), 1381-1423.

Bloch, P. H., Bush, R. F., \& Campbell, L. (1993). Consumer 'Accomplices' in product counterfeiting: A demand side investigation. Journal of Consumer Marketing, 10(4), 27-36.

Catch the counterfeits! (2007, February 5). MBC NewsDesk. Retrieved January 13, 2009, from http://imnew.imbc. com

Chakraborty, G., Allred, A., Sukhdial, A. S., \& Bristol, T. (1997). Use of negative cues to reduce demand for counterfeit products. Advances in Consumer Research, 24, 345-349.

Chan, A., Wong, S., \& Leung, P. (1998). Ethical beliefs of Chinese consumers in Hong Kong. Journal of Business Ethics, 17(11), 1163-1170.

Chang, E. Y., \& Lee, H. H. (2007). The examination of the group differences in buyers and non-buyers of counterfeit fashion goods-Focused on Korean consumers-. Journal of the Korean Society of Design Culture, 13(1), 74-86.

Commuri, S. (2009). The impact of counterfeiting on genuine-item consumers' brand relationships. Journal of Marketing, 73(3), 86-98.

Conner, K. R., \& Rumelt, R. P. (1991). Software piracy: An analysis of protection strategies. Management Science, $37(2), 125-139$.

Cordell, V. V., Wongtada, N., \& Kieschnick, Jr. R. L. (1996). Counterfeit purchase intentions: Role of lawfulness attitudes and product traits as determinants. Journal of Business Research, 35(1), 41-53.

Ha, S. J., \& Lennon, S. J. (2004). Purchase intent for fashion counterfeit products: Ethical ideologies, ethical judg- 
ments, and perceived risks. Clothing and Textiles Research Journal, 24(4), 297-315.

Hong, B. S., \& Suk, H. J. (2009). Understanding of intellectual property rights in fashion industry and its applications-Focusing on design copyright, trademark, counterfeit issues-. Fashion Information and Technology, 6, 34-42.

Hustak, A. (1990, August). Ritzy ripoffs. The Gazette, p. 31.

Kay, H. (1990, July). Fake's progress. Management Today, 54, pp. $54-58$.

Kim, W. O. (2009). Protection of intellectual property in fashion industry. Fashion Information and Technology, $6,27-33$.

Korea's luxury market: Demanding consumers, but room to grow. (2011, September). McKinsey \& Company: Consumer \& Shopper Insights. Retrieved September 25, 2011, from http://csi.mckinsey.com/en/Knowledge_by_ region/Asia/South_Korea/Korealuxury.aspx

Kwong, K. K., Yau, O. H. M., Lee, J. S. Y., Sin, L. Y. M., \& Tse, A. C. B. (2003). The effect of attitudinal and demographic factors on intention to buy pirated CDs: The case of Chinese consumers. Journal of Business Ethics, 47(3), 223-235.

Lee, D. D. (2004). Effects of quality and price of counterfeits on evaluation of counterfeit and genuine fashion luxury brands. Korea Marketing Review, 19(1), 97129.

Lee, M. Y., \& Johnson, K. K. P. (2007). Effects of ethical ideologies on the Korean consumers perceptions and purchase intentions of fashion Counterfeits. Journal of Korean Society of Clothing and Textiles, 31(12), 17931802.

Lee, S. H. (2004). Consumers' purchasing behavior and consumer ethics on fashion counterfeits among Korean, Japanese, and Hong Kong consumers. Journal of the Korean Society of Clothing and Textiles, 28(11), 14381447.

Lee, S. H., \& Kim, M. Y. (2007). A study on the effect of attitude toward fashion counterfeits on variables related to luxury brand. Journal of the Korean Society of Clothing and Textiles, 31(9/10), 1431-1441.

Lu, L. C., \& Lu, C. J. (2010). Moral philosophy, materialism, and consumer ethics: An exploratory study in
Indonesia. Journal of Business Ethics, 94(2), 193-210.

Nia, A., \& Zaikowsky, J. L. (2000). Do counterfeits devalue the ownership of luxury brands? Journal of Product \& Brand Management, 9(7), 485-497.

Nill, A., \& Shultz II, C. J. (1996). The scourge of global counterfeiting. Business Horizons, 39(6), 37-42.

Seoul emerges as new hub for luxury business. (2010, March 30). The Korea Herald. Retrieved July 30, 2011, from http://www.koreaherald.com/business/Detail.jsp?news MLId=20090714000063

The economic impact of counterfeiting and piracy: Executive Summary OECD, Paris. (2007). OECD. Retrieved December 11, 2010, from http://www.oecd.org/dataoecd/13/12/38707619.pdf

Tom, G., Garibaldi, B., Zeng, Y., \& Pilcher, J. (1998). Consumer demand for counterfeit goods. Psychology and Marketing, 15(5), 405-421.

Retail sales figure. (2011, August). Ministry of Knowledge Economy. Retrieved September 10, 2011, from http:// www.mke.go.kr

Wee, C. H., Tan, S. J., \& Cheok, K. H. (1995). Non-price determinants of intention to purchase counterfeit goods: An exploratory study. International Marketing Review, 12(6), 19-46.

Wotherspoon, D., \& Cheng, M. (2009, October 1). Web of deceit: The global impact of counterfeit products. Risk Management, 56(8), pp. 32-37.

Yao, J. T. (2005). How a luxury monopolist might benefit from a stringent counterfeit monitoring regime. International Journal of Business and Economics, 4(3), 177-192.

Yoo, J. M. (2011). The impact of counterfeiting on the consumers' attitude toward luxury brand-Comparison study between genuine-item vs. counterfeit-item consumers-. Journal of Consumer Studies, 22(2), 113-137.

Yoo, B. H., \& Lee, S. H. (2011). Assymmetrical effects of past experiences with genuine fashion luxury brands and their counterfeits on purchase intention of each. Journal of Business Research. doi:10.1016/j.jbusres. 2011.10.018

Yu, H. K., \& Lee, Y. S. (2002) Fashion counterfeit purchase and consumer characteristics. Proceedings of the Korean Society of Clothing and Textiles, Fall Conference, Korea, 181-182. 